Brit. J. industr. Med., 1951, 8, 288.

\title{
PLASTIC SPLINTS AND APPLIANCES IN INDUSTRIAL ORTHOPAEDICS
}

\author{
BY \\ JOHN T. SCALES \\ From the Plastic Research Unit, Institute of Orthopaedics (University of London), \\ Royal National Orthopaedic Hospital, Stanmore
}

Many patients with orthopaedic conditions are able to continue their normal work if they are supplied with a light weight splint. In many instances they must be capable of withstanding the various cutting, grinding, cooling, and lubricating fluids which cause plaster of Paris to disintegrate rapidly.

It is only proposed to mention ambulatory appliances, although methods of manufacture-and materials are equally applicable to " bed splints".

The materials to be described are not suitable for instruments such as walking calipers, as at present there is no synthetic material equivalent in strength to steel on a volume for volume basis.

The orthopaedic surgeon and industrial medical officer have to treat two main groups of patients : (1) those who suffer an injury requiring prompt application of an immobilizing splint, e.g., a fractured scaphoid, for which a negative plaster cast cannot be taken; and (2) those who are suffering from a condition which may require (a) partial immobilization, and limitation of movement (e.g., tenosynovitis, sciatica); (b) prevention of deformity (e.g., peripheral nerve injuries); and (c) assistance in restoration of function (e.g., tendon repair or amputations).

\section{Properties}

Materials used for splint manufacture should possess the following properties : ease and speed of manipulation, durability, resistance to fatigue strain, light weight, inertness to chemical agents, porosity and cheapness, freedom from irritants causing dermatitis, and, in some cases, radiolucency.

A number of synthetic materials come nearer to the ideal than the traditional moulded leather and "celluloid" which must be reinforced with duralumin or steel. The ideal plastic will be one which, after direct application to a patient or mould, will polymerize rapidly to form a rigid, or in some cases a semi-rigid cast or, alternatively, one which is soluble in a high concentration, about $80 \%$, in a cheap solvent such as water. The setting time should not exceed 15 to 20 minutes.

\section{Materials and Manipulation}

Cellulose Acetate and Glass Fabric*.-This type of bandage was first described by Kulowski, French, and Erickson (1944) and has been widely used in the United States of America. It is produced as a knitted bandage in varying widths, and consists of $20 \%$ glass fibre and $80 \%$ cellulose acetate. When quickly dipped into a setting fluid which contains acetone, methylsalicylate, and pentane, the acetate becomes partially soluble and the bandage can be readily applied. Stockinette should be used under the bandage so that the ends of the splint may be finished off by turning the stockinette back over the free edge in order to prevent the glass fibre from irritating the skin. The bandage must be applied with minimum tension, each layer being well smoothed into the preceding one. Moulding is improved if a crepe bandage is wrapped round the cast and held in position for a few minutes after applying the final layer. Setting time is reduced by playing a current of warm air over the surface. The maximum strength of the cast is not achieved for 24 hours, as is also the case with plaster of Paris. "Immobilization time" is longer than with plaster. The cast is inflammable until all fluid has evaporated, and the patient should not be allowed to come into contact with any process where there are naked lights. After this, the risk is no greater than with wood. The finished splint (Fig. 1) is light, porous, unaffected by water, and radio-translucent. Non-bivalved tubular splints are very satisfactory if care is taken in their production. Although a slight $x$-ray shadow is caused by the material,

* Cellulose acetate and glass fabric is produced in Great Britain by John T. Smith \& Nephew Ltd., Hull, under the trade name of Glassona. Manufactured in the United States of America by the Tower Co. Inc., Seattle, U.S.A., under the trade name of Airlite. 


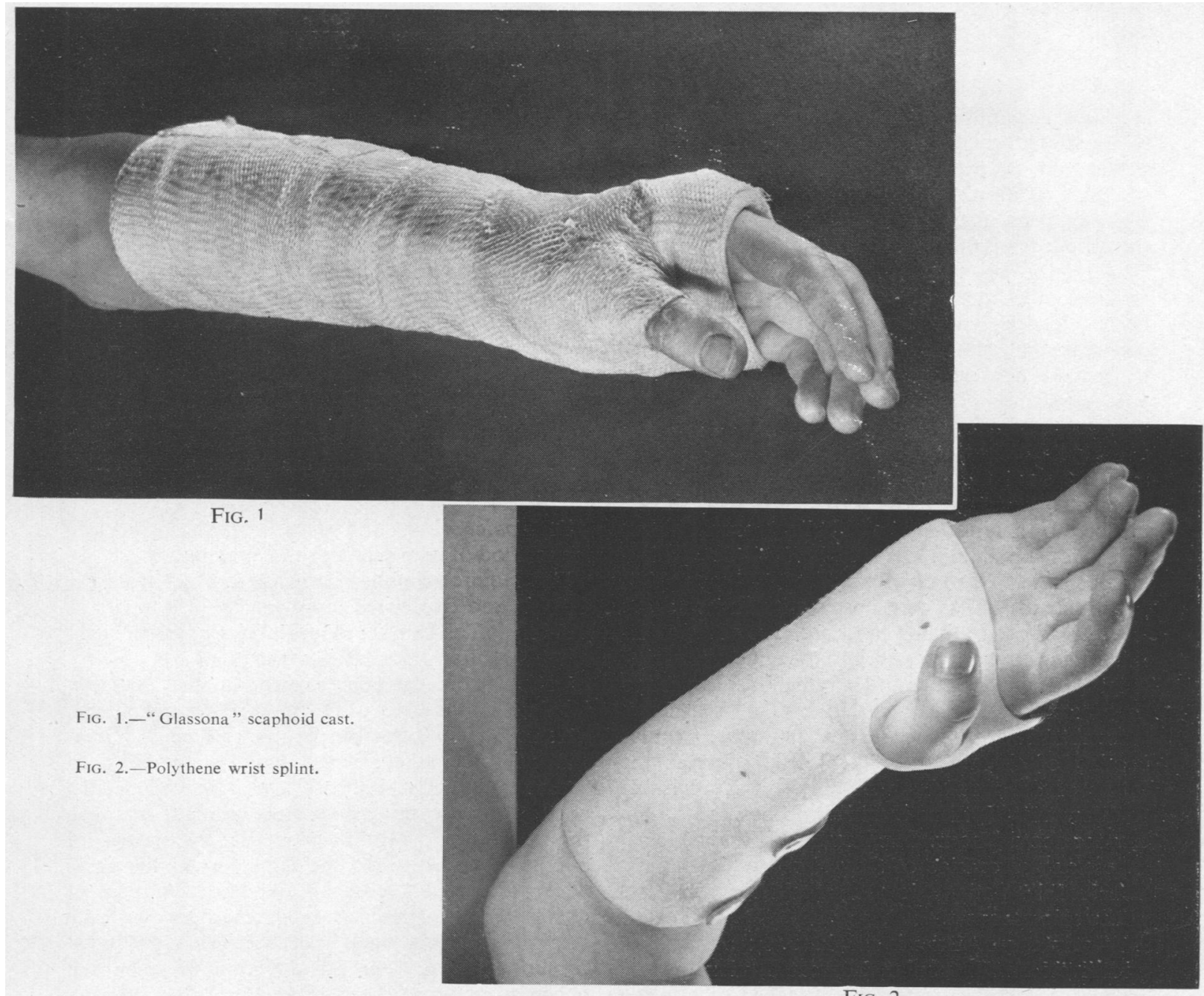

fracture repair can be followed without removal of the appliance, although a final check radiograph, especially for a fractured scaphoid, should be carried out after the cast has been removed.

Immersion in water has no effect on the splint ; the stockinette, however, takes some time to dry out. This material is very useful for arm and leg encircling splints (Group 1).

Polyethylene (Polythene)*.-Polythene is the chemical name of a thermoplastic material used in industry for electrical insulation, chemical ware, and for other applications where an inert, semi-rigid material is required. In sheet form it is admirable for the manufacture of appliances which do not require to be completely rigid, e.g. cervical collars and forearm splints (Fig. 2). It is a solid polymer

* Polyethylene (Polythene) is produced in England by Imperial Chemical Industries Ltd. (Plastics Division), under the trade name of Alkathene. of the gas ethylene, melting at $120^{\circ} \mathrm{C}$. At normal body temperature it is tough and somewhat flexible. It is one of the lighter synthetic materials, having a specific gravity of 0.93 . It is translucent to light in all parts of the spectrum. Splints do not require to be removed during sunlight treatment. It is unaffected at body temperature by all organic solvents, but over some months of wear it may develop a slight yellowish tinge. This is due to ultra-violet light oxidation, but the strength and durability of the material do not appear to be impaired. A flesh-tinted polythene containing an anti-oxident is now available for medical purposes.

Manipulation of Sheet Polythene.-The most suitable thicknesses of sheet are $\frac{1}{8}$ in. and $\frac{3}{16} \mathrm{in}$. A spinal jacket will be used to illustrate the procedure, the jacket being moulded in two halves.

Overall measurements of the positive plaster cast are taken, and two pieces of polythene of the 
appropriate sizes are cut. Offcuts of the material are used as reinforcements, as most jackets require to be strengthened down the spine. The sheet is placed on a perforated asbestos board which has been lightly dusted with French chalk (Fig. 3). This powder acts as a " release" preventing the softened polythene from adhering to the asbestos. The reinforcing strip is placed in the position required, the areas of contact having previously been cleaned with benzene. It is absolutely essential that no powder or grease is allowed to remain between the opposed surfaces, otherwise satisfactory fusion will not take place. The asbestos board and polythene are placed in an oven, preferably with a thermostat set at $120^{\circ} \mathrm{C}$., and left until the sheet and reinforcing strip are completely transparent. The rate of heating should not be too rapid, otherwise bubbling occurs. When ready for moulding, the polythene is in a semiviscous state. A piece of stockinette of the appropriate size which has been dusted with French chalk is stretched carefully into position. The edges of the reinforcing strip are pressed into the underlying sheet (Fig. 4). The stockinette and polythene are applied to the plaster cast (Fig. 4a). A thin sheet of "durestos" (described later) allows slower and more regular cooling of the polythene, and thus prevents the inside of the moulding wrinkling. It is advisable to allow the polythene to remain in position on the cast for about $\frac{3}{4}$ hour. The imprint of the stockinette is left on the outside of the polythene, and this is preferred by patients to the smooth, wax-like feel of the original sheet.

A strip of polythene is moulded to form a hinge and riveted with tubular, bifurcated, nickel-plated rivets. A locking zip-fastener attached to a lacing is fitted to the other side of the jacket. This lacing adjustment allows for any increase in size of the patient, and the zip-fastener is the most simple method for everyday application of the appliance (Figs. 5 and 6).

With the exception of an oven, no expensive equipment is required. Splints are far quicker to produce than similar appliances made from moulded leather or cellulose acetate reinforced with steel. The cost of production is approximately half. They are light in weight and are readily kept clean. At the present time, all old appliances are reclaimable for scrap.

\footnotetext{
"Durestos"(Resinated Asbestos Felt).-“Durestos" is a thermosetting, laminating felt used in industry for the manufacture of many lightweight components.
}

* Durestos (resinated asbestos felt) is produced by Turner Bros., Rochdale, under the trade name of Durestos. It is a phenolformaldehyde resinated asbestos laminating felt.
It consists of asbestos fibre which has been treated with partially condensed phenolformaldehyde resin. This resin, on further heating, condenses to form an insoluble solid, the asbestos acting as a reinforcing filler. The sheets are available in three thicknesses and become workable when they are damped with water. The resin is soluble in spirit or acetone and these may be used as alternative wetting agents. Care must be taken, however, that the moulding is not placed in the oven before inflammable solvents have evaporated.

Preparation of the Cast.-The plaster cast is painted with a solution of cellulose acetate, and then wiped over with a film of petroleum jelly to prevent the resin from penetrating the plaster and to allow of easy removal of the cured moulding.

Manipulation.-A hip spica is used to illustrate the method of manipulating this material.

The required number of pieces are cut from the dry felt and dampened, applying as little water as possible. The felts should be left for approximately a quarter of an hour, after which time it is possible to stretch the material readily in the direction required. If the edges of the material are well teased, satisfactory lap joints can be made (Fig. 7). Great care must be taken, when applying the felts, to ensure that each layer is firmly bonded to the next, and that no air pockets are left between the laminates. Reinforcement is by means of offcuts placed between the laminates in the areas where increased strength is required. A piece of muslin firmly stretched over the last laminate prevents "spring back" of the felts. Strips of muslin are placed in the direction of re-entrant curves to prevent " bowstringing" of the laminates (Fig. 8). A final coat of cellulose acetate solution is applied and the evaporation of the solvent helps in the consolidation of the moulding. Its main purpose, however, is to give a smooth finish to the cured laminate. The cast is placed in an oven, and allowed to cure at $70^{\circ} \mathrm{C}$. for about eight to 10 hours. Temperatures above this are liable to cause delamination. The time period depends on the size of the cast and the dryness of the plaster.

The cured splint is cut from the cast with an electric, circular handsaw ; $\frac{1}{8}$ in. ventilation holes are drilled, and the inside coated with a water emulsion of unplasticized polyvinyl acetate. It is then put back into the oven for five minutes to form a skin.

After fitting to the patient, the splint is coated with a metal-based cellulose primer, followed by a flesh-coloured cellulose lacquer. Buckles, straps and laces, etc. are then attached (Fig. 9).

Splints may be washed with warm, soapy water, and are unaffected by normal body secretions, sea- 


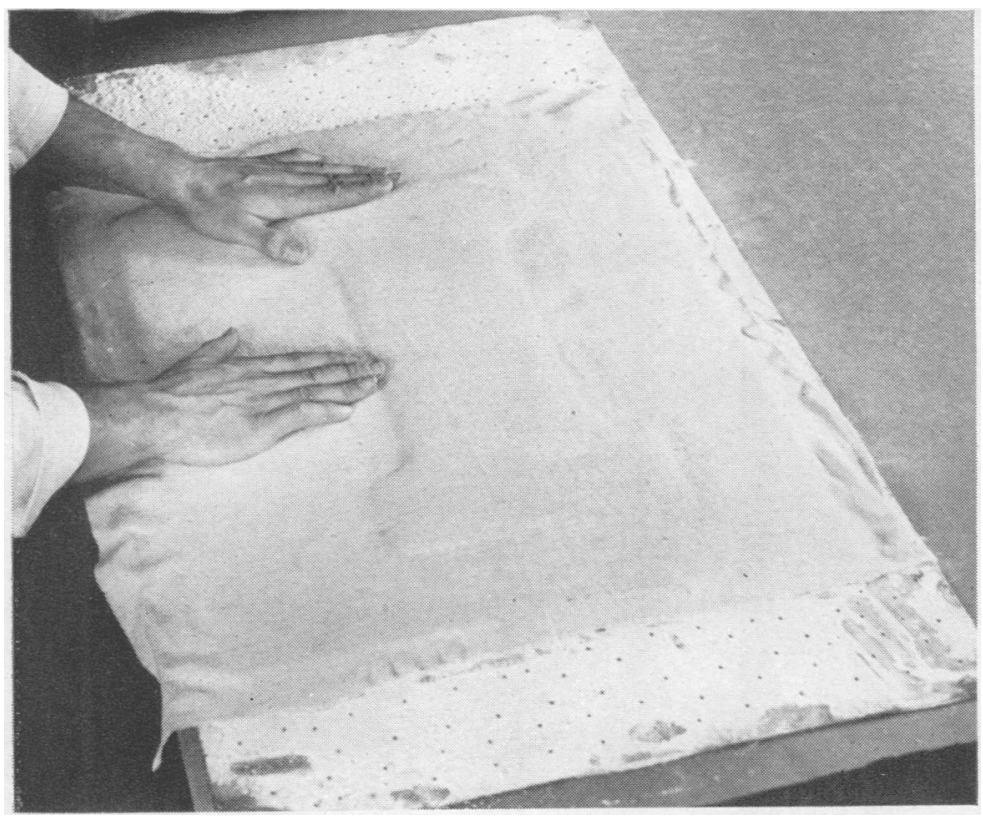

Fig. 3.-Polythene sheet on asbestos board with reinforcing strip in position.

FIG. 3a.-Transparent sheets and reinforcing strip ready for moulding.

Fig. 4.-Application of stockinette to sheet.

Fig. 4a.-Polythene applied to cast.

Fig. 4

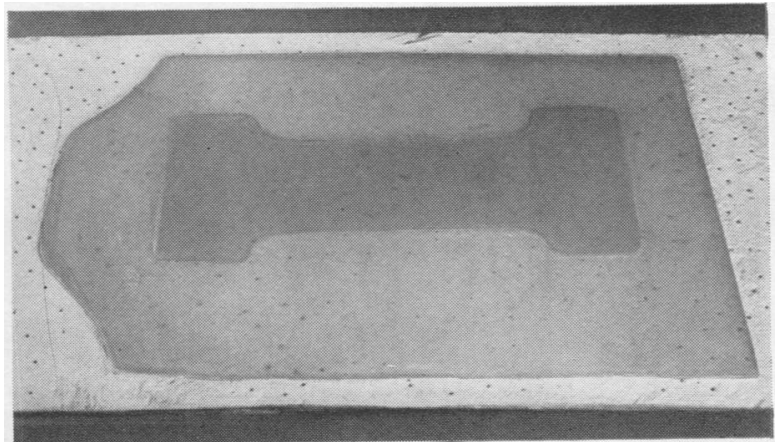

Fig. 3

FIG. $3 a$

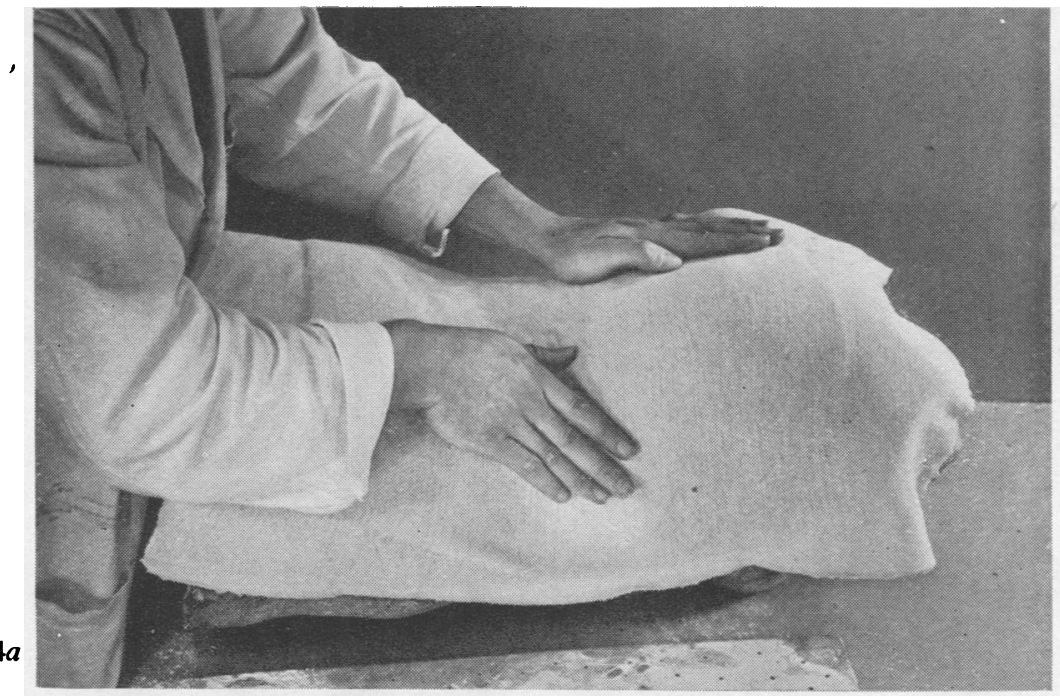

Fig. $4 a$ 


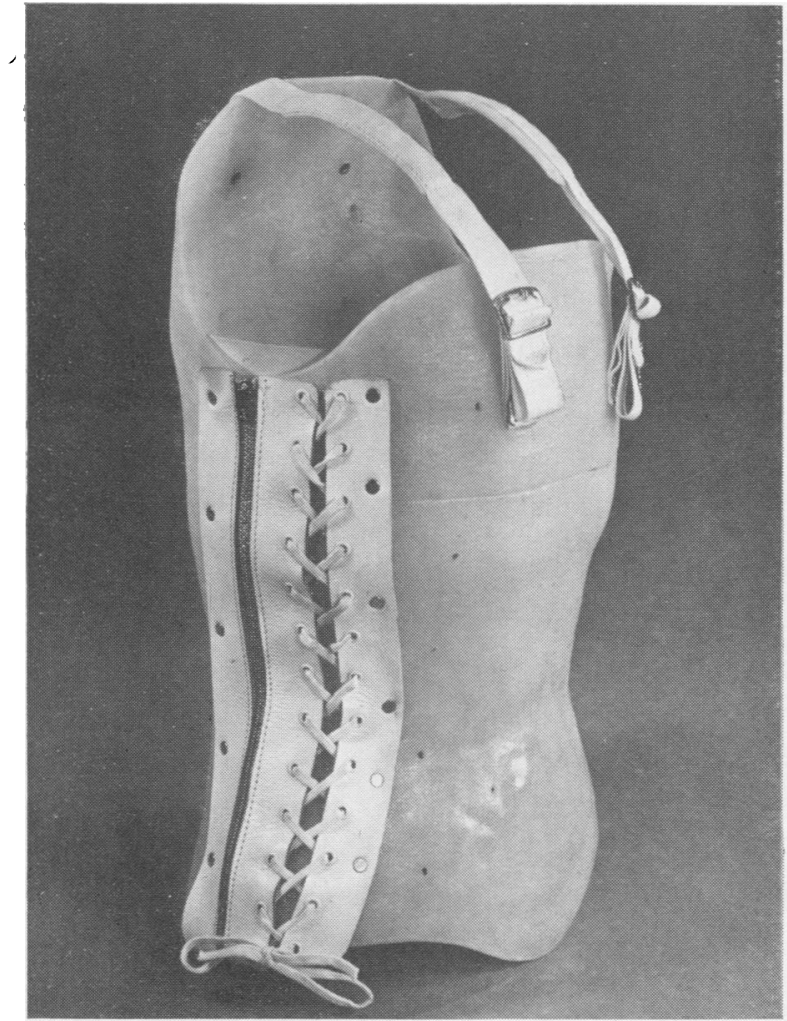

FIG. 5.-Finished jacket.

Fig. 6.-Patient after spine graft, wearing polythene jacket with abdominal corset.

Fig. 7.-Application of felt to cast. Note teased edge.

FIG. 8.-Moulding ready for curing. Note position of muslin strips which prevent "bowstringing" of felt across re-entrant curves.

FIG. 5
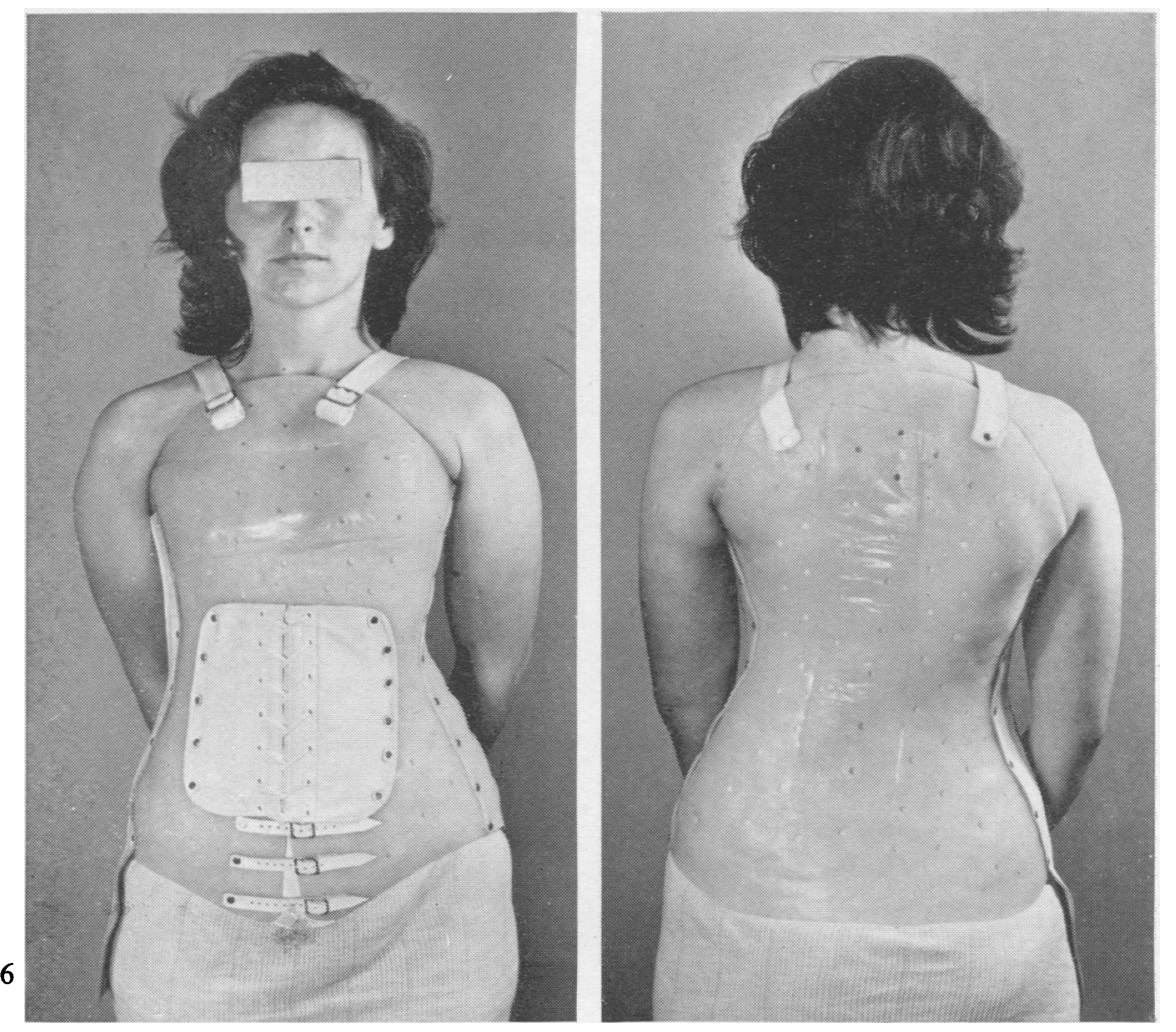

FIG. 6 


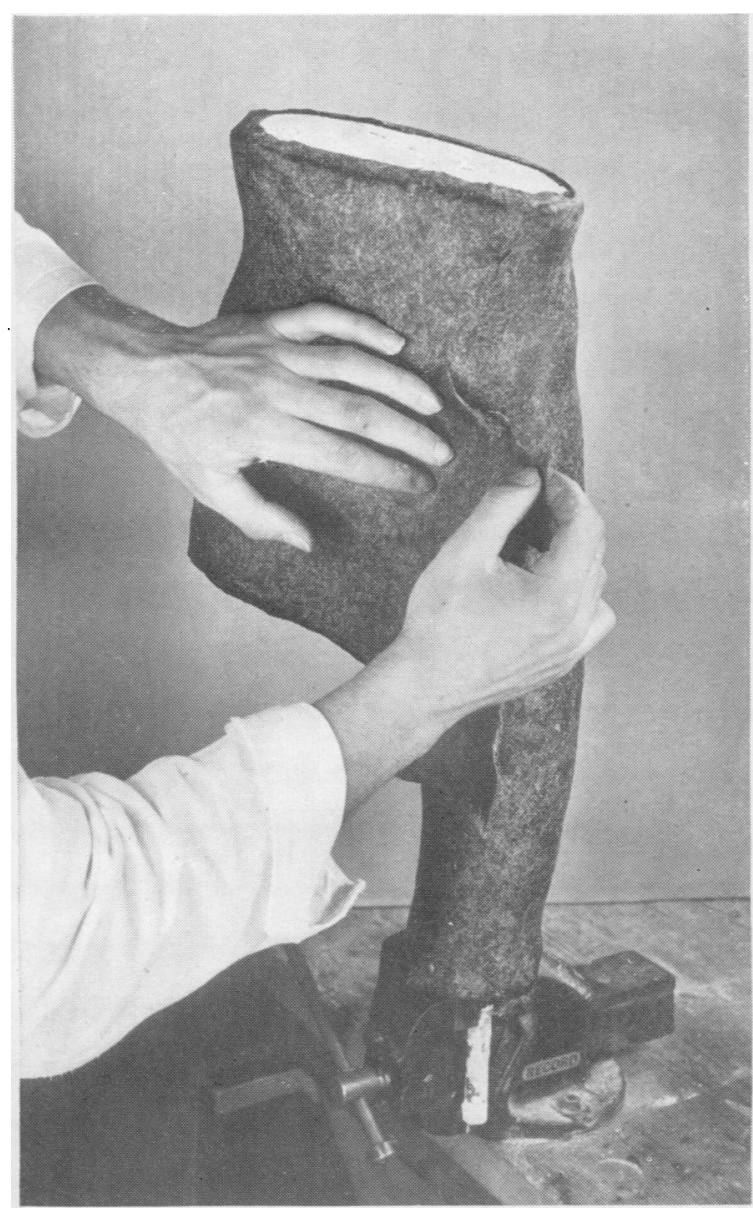

Fig. 7

water, etc. They may also be used for treatment in chlorinated swimming pools.

The finished appliance is light in weight, rigid, and requires no metal reinforcement. It does not distort with use and is non-inflammable.

This material is most satisfactory for rigid splints, used in the treatment of patients in Groups $2 \mathrm{a}$ and 2c, for example, spicas, pylons, rigid spinal jackets, and long leg gutters (Fig. 10).

There appears to be no risk of contact dermatitis with the cured material and no cases have been reported.

Perspex (Polymethyl Methacrylate)*.-This is a thermoplastic material with a varying degree of rigidity, depending on its thickness. The plasticized sheet material ( $\frac{1}{16}$ in. to $\frac{3}{16} \mathrm{in}$.) is most suitable for small splints and parts of rehabilitation appliances (Fig. 11a, b, c), but it is not suitable for large appliances such as pylons or hip spicas, as it is

* Perspex (Polymethyl methacrylate) is produced in the United Kingdom by Imperial Chemical Industries under the trade name of Perspex. Known in the United States as Lucite and Plexiglas.

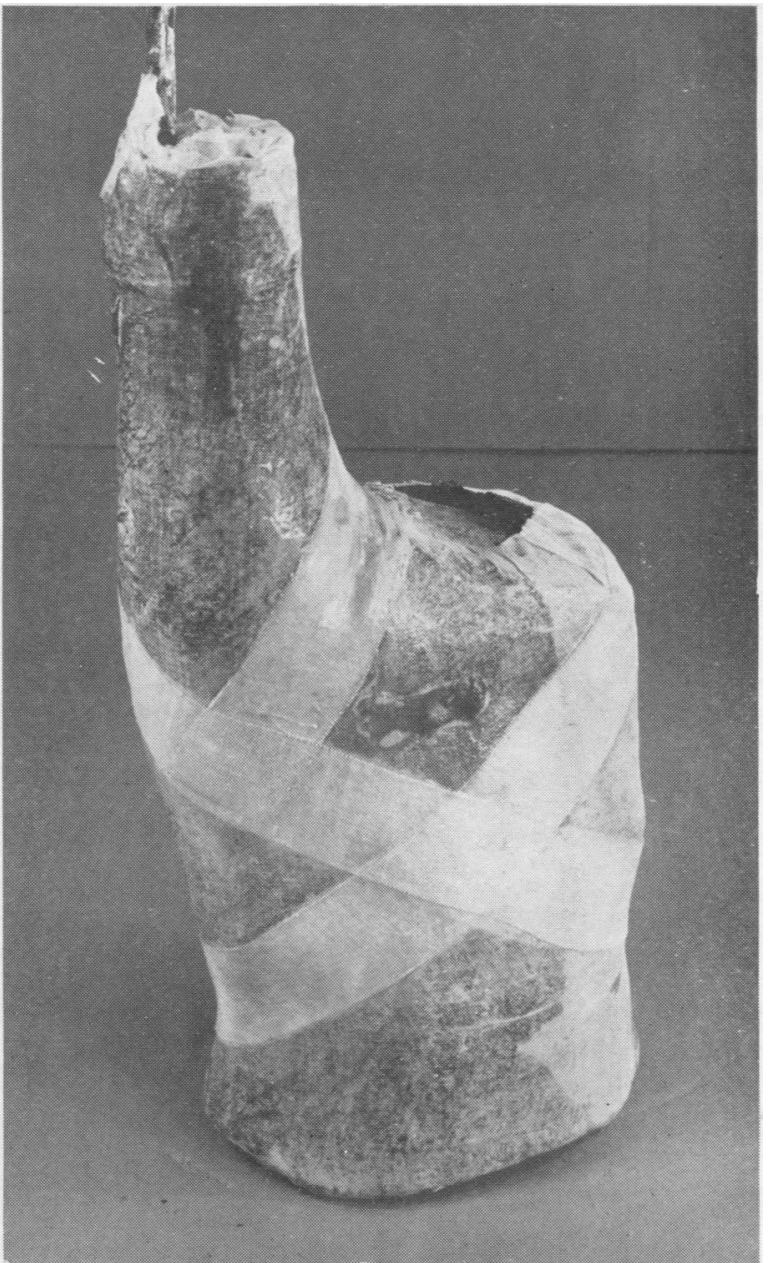

Fig. 8

difficult, without suitable equipment, to mould complex shapes and, should the mouldings break, the sharp edges left may cause considerable injuries.

Method of Manipulation.-Small supporting splints can be made either by pressing the material softened by heat between male and female plaster casts, or, if the shape is relatively simple, it can be pressed into contact with a positive plaster cast, the operator wearing asbestos gloves. Minor adjustments can be made by manipulating locally heated areas.

As with polythene, the appropriate size of sheet is prepared and placed on an asbestos board, in any form of oven which will give a temperature of $140^{\circ} \mathrm{C}$. The sheet should not be overheated, as breakdown of the material occurs. When ready for moulding it is soft and rubberlike. Unlike polythene, it has considerable "springback" in its mouldable state, and must, therefore, he held in contact with the cast while cooling. Airholes are drilled for ventilation and should be countersunk on the side next to the patient's skin. They should not be more than 


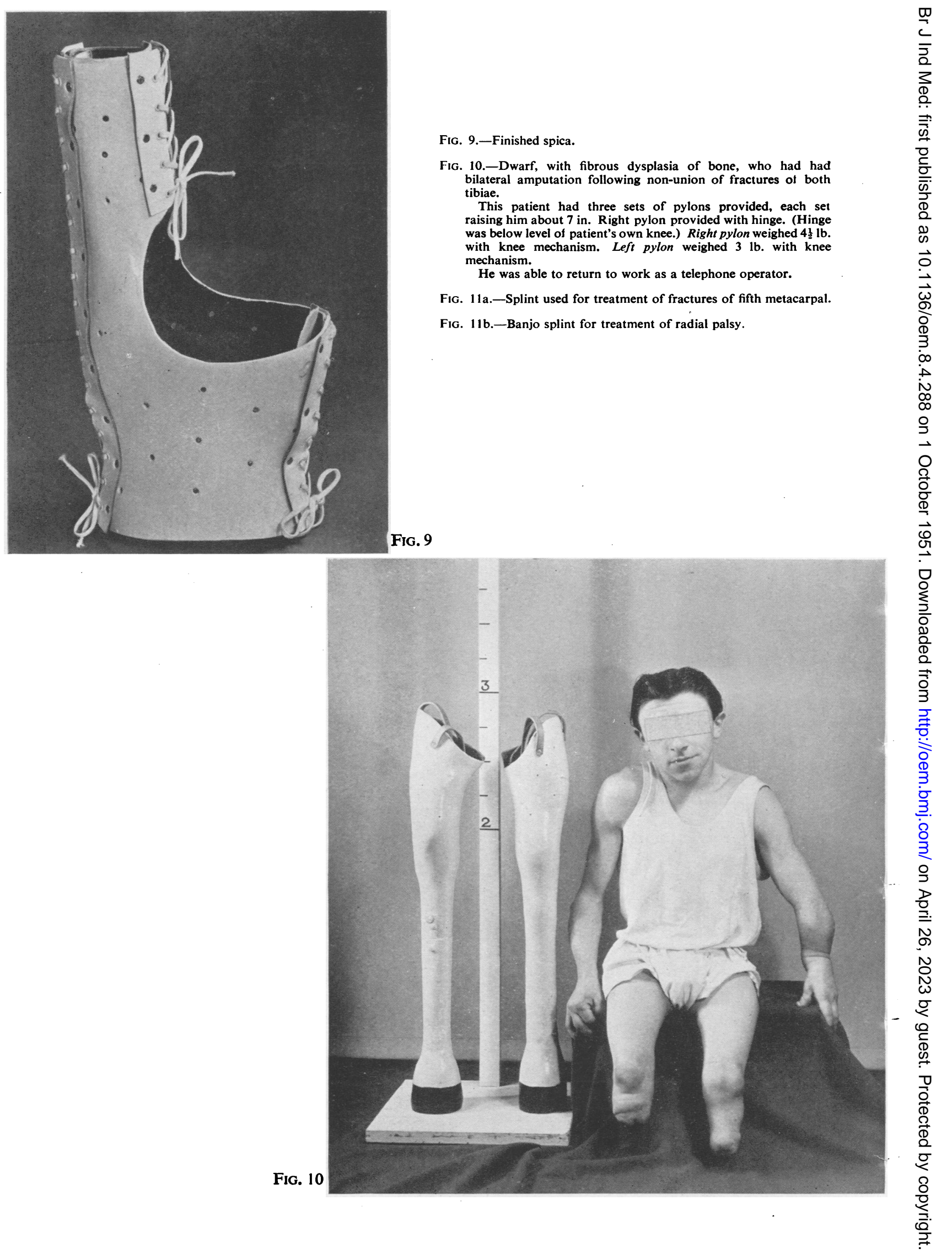


PLASTIC SPLINTS AND APPLIANCES

295

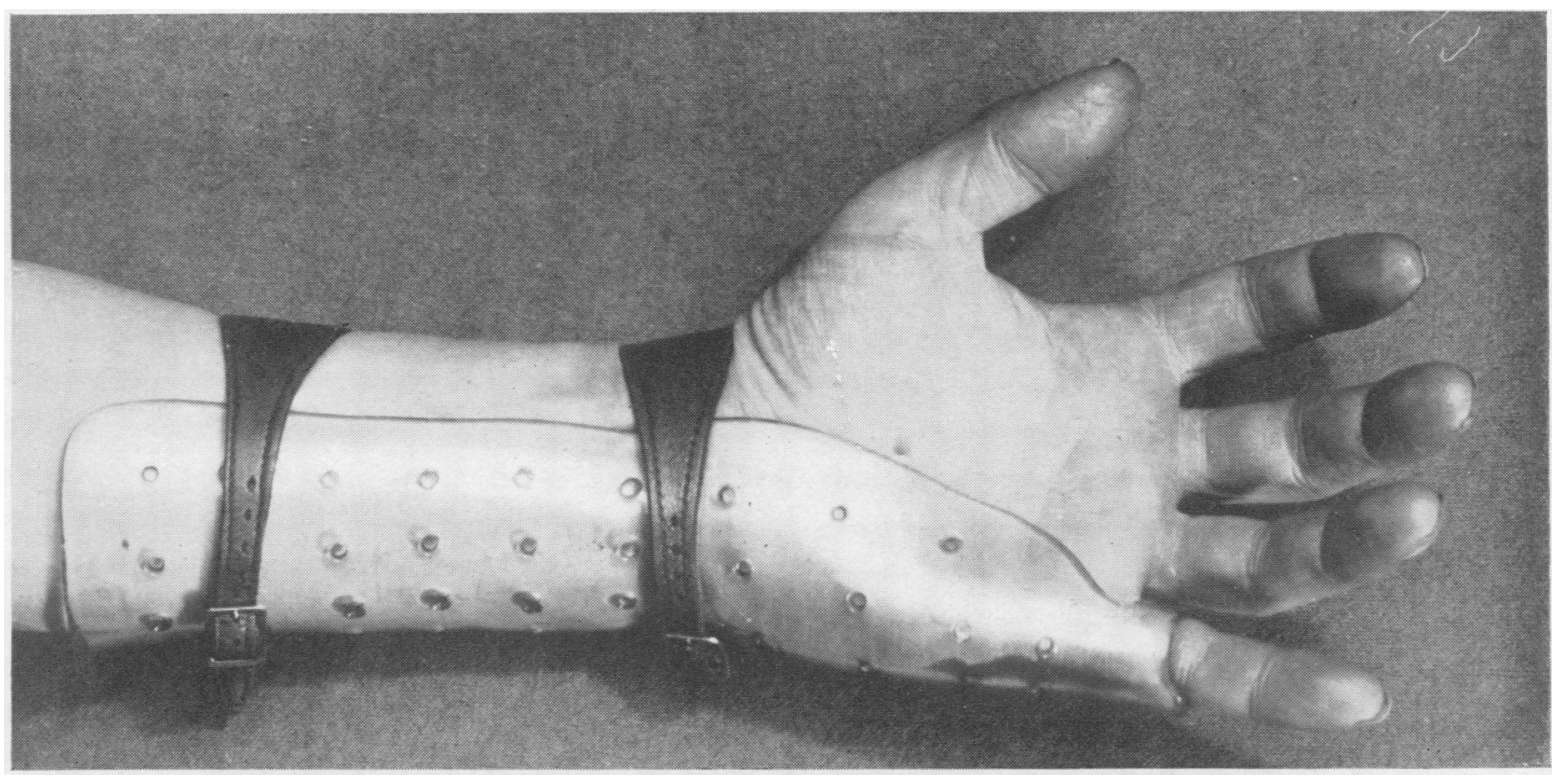

FIG. $11 a$

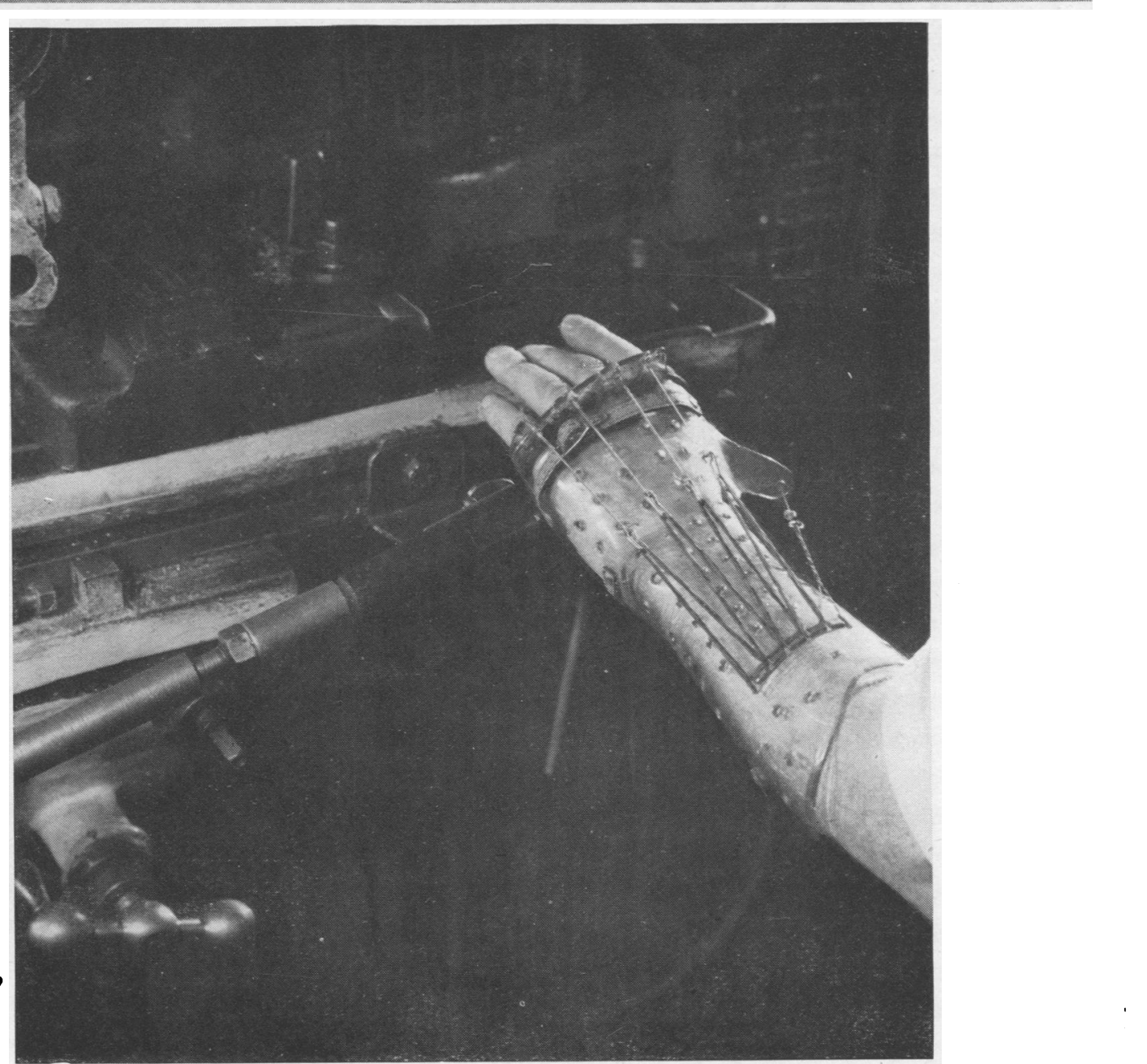

$\underline{\underline{w}}$

흘

3

응

$\overrightarrow{\vec{F}}$

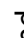

$\frac{\bar{c}}{\overline{0}}$

$\frac{\bar{c}}{\mathrm{o}}$

के

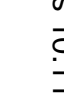

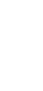




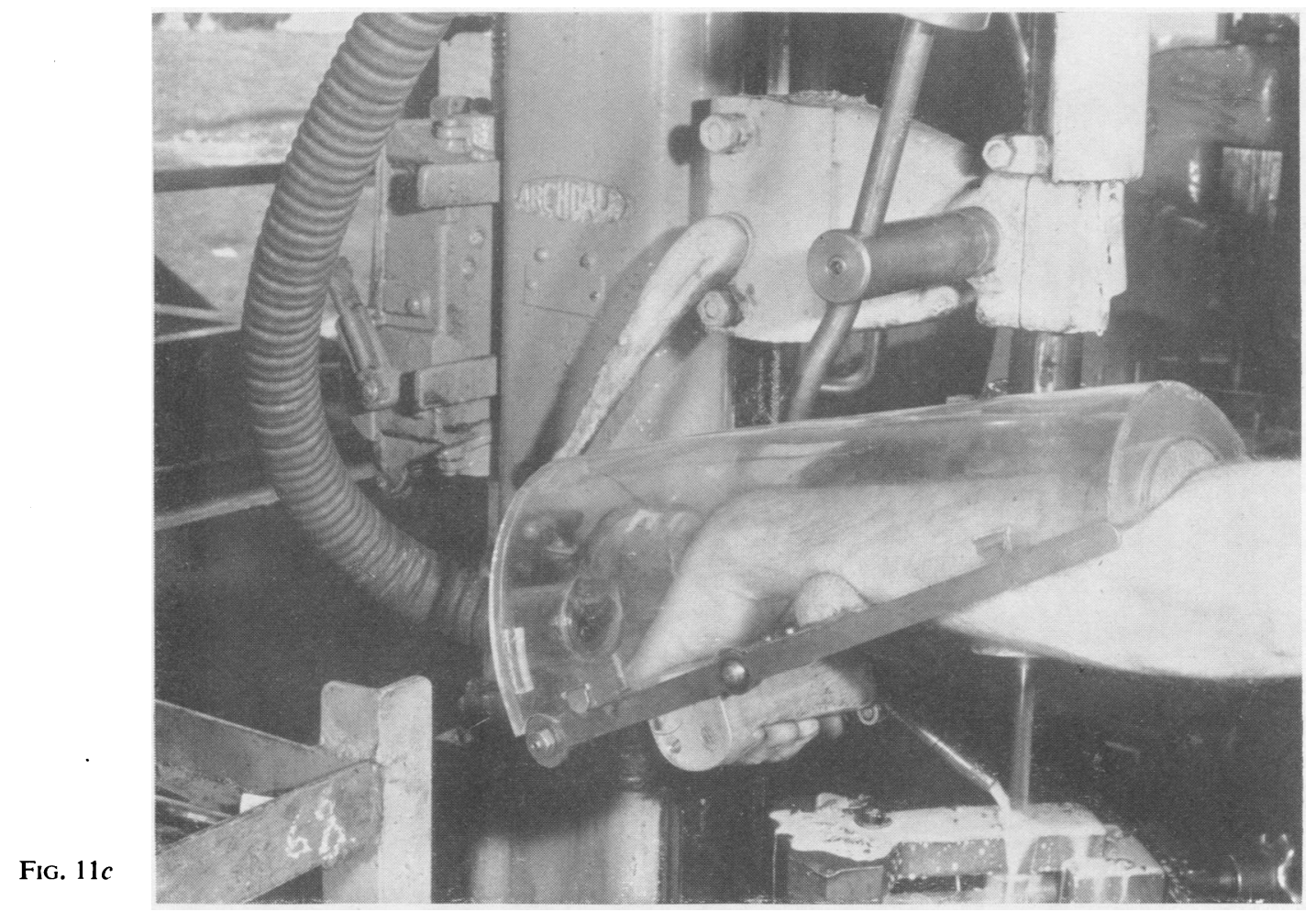

Fig. 11c.-Warm air box for treatment of injuries and rheumatoid conditions of the hand and wrist (used instead of wax baths). Apparatus designed to give active flexion and extension of wrist while operating machine.

Fig. 12.-Opponens paralysis splint. There is no palmar bar. Each end of the splint turns over the thena and hypothena eminences.

Figs. 11a, $b, c$ by kind permission of Vauxhall Motors Ltd., and Fig. 12 of E. J. Nangle from "Instruments and Apparatus in Orthopaedic Surgery".
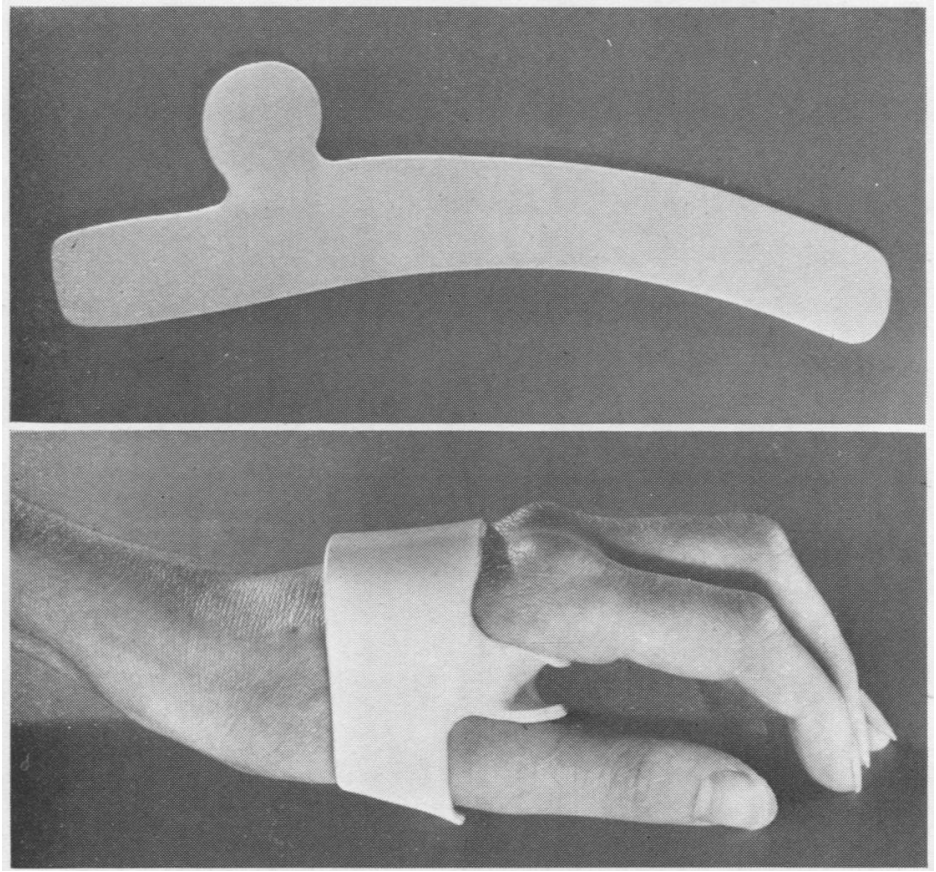

Fig. 12 
$\frac{1}{8}$ in. or $\frac{3}{16}$ in. in diameter in weight-bearing areas, otherwise small blisters may be formed. Appliances may be kept clean by washing with warm, soapy water, and are unaffected by normal body secretions or by fluids used in industry. They are light in weight, and do not distort with use. The material is dissolved by chloroform, acetone, benzene, and trichlorethylene.

Splints made from this material are most suitable for treatment of certain conditions in Group 2, particularly tenosynovitis round the wrist joint (Thompson, Plewes, and Shaw, 1951).

Where a slightly more resilient material with better fatigue resistance is required, certain grades of rigid polyvinyl chloride and co-polymers of polyvinyl chloride and acetate are useful. Fig. 12 shows a splint used in the treatment of opponens paralysis. A standard shaped blank is locally heated over a Bunsen burner and moulded freehand to the form required. This splint holds the thumb in mid-opposition, but allows freedom of abduction and extension, the resilience of the material restoring the thumb to the correct position.

\section{Summary}

There are now available to the orthopaedic surgeon, the industrial medical officer, and the appliance manufacturer synthetic materials which can be used to produce, in many cases, more efficient lightweight appliances in less time and at lower cost than hitherto.

The choice of the material used depends on the type of appliance to be made and the facilities available for its manufacture.

The conditions of work of the patient must also be taken into consideration. With the exception of the cellulose acetate and glass bandage, there is at present no plastic material which can be applied satisfactorily direct to the patient.

I should like to thank Mr. T. Whitly, of the Medical Photographic Department of the Institute of Orthopaedics, for the photographs reproduced as Figs. 1, 2, 3, $3 a, 4,4 a, 5,6,7,8,9$, and 10 .

\section{REFERENCES}

Kulowski, J., French, A. M., and Erickson, H. R. (1944). Amer. J. Surg., 66, 315.

Thompson, A. R., Plewes, L. W., and Shaw, E. G. (1951). British Journal of Industrial Medicine, 8, 150. 